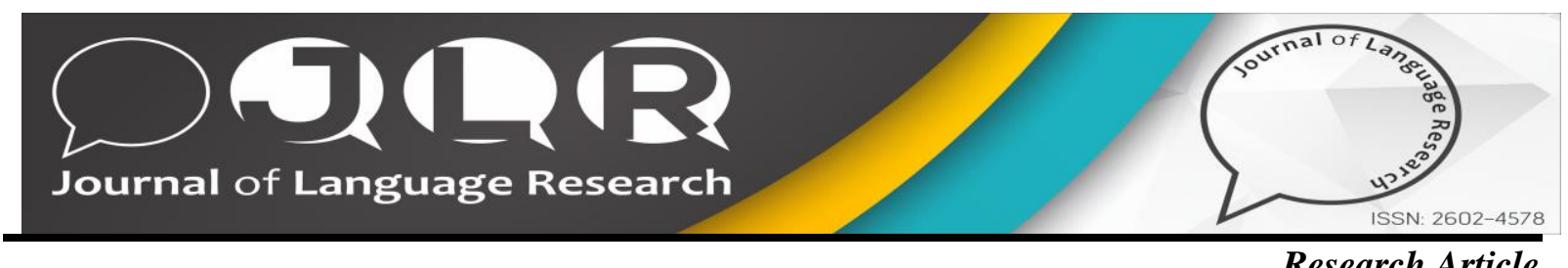

\title{
Teaching Grammar Through Form-Focused Instruction: The Case of Teaching Modal Verbs to Turkish EFL Learners
}

\author{
Hüsnü GÜMÜŞ ${ }^{1}$, ID Pamukkale University, husnug@pau.edu.tr
}

Recommended citation: Gumus, H (2021). Teaching Grammar through Form-Focused Instruction: The Case of Teaching Modal Verbs to Turkish EFL Learners. Journal of Language Research (JLR), 5(1), 1-16, DOI: $\underline{10.51726 / \mathrm{j} 1 \mathrm{r} .886107}$

\begin{abstract}
The present study attempted to explore the effectiveness of form-focused-instruction (FFI) in a context where English is learned as a foreign language. In particular, the purpose of the study was to investigate the effectiveness of the planned focus-on-form instruction (FoF) in comparison with focus-onforms (FoFs) in the acquisition of a set of modal verbs. The participants of the study were 8th grade students $(n=37)$ studying at a middle school in Denizli. The present study adopted a mixed-method research design. The quantitative part involved a pretest, a treatment stage, and a posttest while the qualitative part consisted of written semi-structured interviews. The data obtained from the pretest and posttest were statistically analyzed through SPSS 17.0 with the aim of measuring the effectiveness of the two instructional treatments. As for the qualitative part, interviews were translated into Turkish and the data was subjected to content analysis and thus analyzed through pattern- coding process to identify recurrent themes. At the end of the study, it was found that planned FoF instruction was more effective than FoFs instruction in the participants' learning of target forms. In addition, at the end of the content analysis, it was found that the participants favored planned FoF instruction because they benefited from guessing the meanings out of the context as it helped them retain the knowledge for a longer period of time. In addition, the participants stated that their exam scores have been positively affected by planned FoF instruction.
\end{abstract}

Keywords: Focus on form, Focus on forms, Planned focus on form, Grammar Teaching, Modal verbs

\section{INTRODUCTION}

Researchers in the field of second language acquisition (SLA) have long debated on how grammar can be best taught in second or foreign language classrooms. According to Ellis (2008), grammar enables language users to have control over their expression and communication in everyday life. Having competence over grammatical structures together with lexical items allow speakers to communicate their emotions and purposes more effectively. During the past few decades, the focus of grammar teaching in classrooms has shifted from an emphasis on language structures to utilizing the language within communicative contexts. Regarding this issue, research and discussions on grammar teaching have recently focused on the distinction between focus-on-forms (FoFs) and focus-on-form (FoF) (Long, 1991).

In FoFs instruction, language is composed of isolated linguistic structures and taught in a predetermined order through explicit explanations of grammar rules and immediate correction of errors

\footnotetext{
${ }^{1}$ ORCID ID: 0000-0002-4055-8805

Submitted: 24.02.2020

Accepted: 14.04.2021

https://doi.org/10.51726/jlr.886107
} 
(Long, 2000). In other words, the teacher actually provides the students with grammatical rules and explanations, which was defined by Harmer as overt teaching (Harmer, 1989). In this instruction, learners are exposed to a typical sequence of "presentation of a grammatical structure, its practice in controlled exercises, and the provision of opportunities for production-PPP" (Ellis, Basturkmen \& Loewen, 2002, p.420). The basis for this approach is that the explicit knowledge regarding grammar rules will become implicit knowledge through adequate practice (De Keyser, 1998). On the other hand, Long (1991) defined focus-on-form as "an instruction that draws students' attention to linguistic elements as they arise incidentally in lessons whose overriding focus is on meaning or communication" (p. 45-46). In other words, FoF is an instructional method through which learners' attention is drawn to linguistic forms within communicative contexts. Therefore, it requires a prerequisite engagement in comprehending meaning before attaining successful learning of linguistic forms (Long \& Robinson, 1998).

Sheen (2002) stated that the two instruction types are different from each other in terms of to what extent a teacher draws students' attention to specific grammar issues. The purpose of FoFs instruction is to help learners gain mastery on grammatical units rather than focusing on communicative purposes. The overall assumption here is that in a language classroom, learners attain language competence only if they are exposed to discrete-point grammar teaching. communication (de La Fuente, 2002; Ellis \& He, 1999; Long, 1991). In FoF instruction, however, learners' main focus remains on processing the message they wish to convey, or the message in the input they are exposed to, though learners' attention is occasionally shifted from meaning to grammatical structures. This shift may happen when learners attempt to solve a comprehension or production problem. In short, during a FoF instruction, the teacher draws the learners' attention to specific linguistic or grammatical units through the use of several meaning focused communicative activities so as to enhance learners' accuracy (Long \& Robinson,1998).

FoFs instruction has been harshly criticized by some scholars for being artificial, dull and teacher-centered since it does not allow learners to be engaged in meaningful communication and interaction which are crucial to language acquisition in a classroom (Long, 2000). When it comes to English teaching in Turkish context, many scholars have stated that English language teaching/learning is obviously problematic (Aktas, 2005; Isik, 2008; Oguz, 1999; Paker, 2007; Tilfarlioglu \& Ozturk, 2007). Many of these problems with English education in Turkey can be attributed to the old-fashioned methods implemented by Turkish EFL teachers who tend to apply traditional grammar instruction by assigning workbook exercises or worksheets, providing explicit grammatical explanations in mother tongue, carrying out quizzes on grammatical forms and repetition drills (Uysal \& Bardakç1, 2014). Such an application, which is associated with FoFs instruction, has called for an action to come up with a better way of teaching the language to learners.

Considering the different features of FoF and FoFs and the problematic issues related to foreign language education in Turkey, this research study aims to explore the effectiveness of formfocused-instruction in a context where English is learned as a foreign language. In particular, the purpose of this study is to investigate the effectiveness of the planned focus-on-form instruction in comparison with FoFs in the acquisition of a set of modal verbs by $8^{\text {th }}$ grade students studying at a middle school in Denizli.

\section{THEORETICAL FRAMEWORK}

In this section, certain aspects of FoF and FoFs will be discussed in two sections to provide insights into both of these instruction types. The first section reviews various definitions of FFI and its sub-categories as well as presenting some basic theories behind this instruction type. The second section presents a number of empirical studies conducted on FFI. 


\section{Focus on Form and Its Underlying Theories}

In literature, it has been stated that there are several underlying theories in SLA that could have triggered the emergence of FoF. For instance, Long (2000) claims that FoF instruction is closely linked with Schmidt's Noticing Hypothesis (Schmidt, 1990). According to this hypothesis, noticing the input in a conscious manner through a cognitive process is crucial for second language acquisition. Another important theory which might have an impact on FoF is Krashen's Monitor Theory. In his theory, Krashen (1981) makes the distinction between learning and acquiring a language, and comes up with non-interface position, which suggests that formal instruction has no place in L2 acquisition. Therefore, there would be no point in learning grammar as comprehensive input is enough to make learners acquire the language. In addition, in his Interaction Hypothesis Long (1991), emphasizes the significant role of interaction and negotiated input in acquisition. Since learners notice their shortcomings and deficiencies in the target language through interacting with other language users, they might become more aware of their grammatical or linguistic inadequacies in their languages through and make the necessary revisions in their existing knowledge. Lastly, Swain's Output hypothesis is considered to be a significant theory which is related to FFI. It has been stated that "If students are given insufficient feedback or no feedback regarding the extent to which their messages have successfully been conveyed, output may not serve these roles" (Swain,1991, as cited in Farrokhi, \& Chehrazad, 2012, p.98).

\section{Different Types of Focus on Form}

In this section, different ways of delivering FoF instruction will be discussed. To start with, Ellis (2005) made a distinction between planned and incidental FoF. In planned FoF, pre-determined linguistic items are handled through activities where the priority is given to meaning rather than linguistic items. This could be achieved through providing input or eliciting output during studentteacher interactions. As the items are selected before a meaning-focused activity, the communicative tasks and activities are also designed accordingly so that the selected linguistic items can be practiced the during meaning focused activities. In short, in planned FoF instruction, the specific linguistic unit becomes a component of the task prior to the teaching practice, and there is an intensive and comprehensive treatment on this selected linguistic unit throughout the task. Incidental FoF (Ellis, 2001) on the other hand, occurs without any deliberate intention while the teacher is implementing meaning-focused tasks and activities, which could aim for different linguistic elements. That is to say, contrary to planned FoF instruction, incidental FoF involves tasks that don't have a specific focus on a pre-determined form but aim for a meaning-focused and content based language teaching. On the other hand, the linguistic items highlighted in incidental FoF occur spontaneously during meaning-focused activities.

Another distinction regarding FoF has been done based on whether it is reactive or preemptive (Ellis,2001). Reactive FoF occurs when learners produce an utterance that contains an observed or perceived error, which might be either dealt with by the teacher or by another learner. On the other hand, in preemptive FoF, the teacher or learner draws attention to form though no actual problem in production has been observed. In other words, reactive FoF deals with an observed or perceived performance problem while preemptive FoF addresses an actual or a perceived inadequacy in the learners' knowledge. In short, both reactive and preemptive focus-on-form instruction could be utilized by teachers to address learners' errors which might otherwise bring about communication breakdowns.

Lastly, there are isolated and integrated FFI types. In the former one, the focus on language form is separated from the communicative or content-based activity while in the latter one the learners' attention is focused on language form during communicative or content-based instruction. This definition is akin to FoF (both planned and incidental) as defined by Ellis (2001) and by Doughty and Williams (1998). In other words, although the form focus occurs within a communicative activity, the language features in focus may have been predetermined by the teacher or they may occur incidentally during the interaction in progress. 


\section{Focus on Form Teaching Techniques}

In this section, a number of teaching techniques of FoF will be presented. Figure 1 below indicates the degree of obtrusiveness of each technique (Doughty \& Williams,1998). Obtrusiveness indicates that grammar structures are presented explicitly by using metalinguistic terms (see Fig. 1). Figure 1 shows that the most implicit technique is the Input flood whereas the most explicit one is the Garden path. The techniques that were applied during the current study will be explained briefly in the following paragraph.

\begin{tabular}{|c|c|c|c|c|}
\hline & Unobtrusive & $\longleftarrow$ & $>$ & Obtrusive \\
\hline Input flood & $\mathrm{X}$ & & & \\
\hline Task-essential language & $\mathrm{x}$ & & & \\
\hline Input enhancement ${ }^{\mathrm{a}}$ & $\mathrm{X}$ & & & \\
\hline Negotiation & $\mathrm{X}$ & & & \\
\hline Recast $^{b}$ & & $\mathrm{X}$ & & \\
\hline Output enhancement & & $\mathrm{x}$ & & \\
\hline Interaction enhancement & & $\mathrm{x}$ & & \\
\hline Dictogloss ${ }^{c}$ & & & $\mathrm{x}$ & \\
\hline Consciousness-raising tasks ${ }^{d}$ & & & $\mathrm{X}$ & \\
\hline Input processing & & & & $\mathrm{x}$ \\
\hline Garden path & & & & $\mathrm{X}$ \\
\hline
\end{tabular}

Fig. 1. Degree of Obtrusiveness of Focus on Form (Doughty \&William,1998, p.258)

(C) Cambridge University Press

Input flood means that a teacher exposes students with a great amount of a linguistic feature whether orally or textually in order that students could acquire plentiful opportunities to come across a specific linguistic feature. (Doughty \& Williams, 1998). On the other hand, input enhancement differs from input flood in that teachers give modified input to learners in order to make the input more noticeable without explicit grammar instruction. In the case of textual input, learners are provided with input which is typographically modified by teachers (e.g. underlining, boldfacing, italicizing, capitalizing, color coding, etc.). Recasts are also commonly used by teachers during FoF instruction. The indirect way of correction provided through recasts is favored by language teachers as it helps them deal with sensitive students who do not prefer receiving explicit correction in front of their peers (Roothooft, 2014). Another activity interaction enhancement refers to a treatment that guides learners to FoF by providing interactional modifications and leads learners to produce modified output within a problem solving task. (Doughty \& Williams, 1998). In other words, a teacher does not give a direct correction as found in recast, but encourages students to notice their errors by making use of teaching techniques such as clarification requests, repetition, metalinguistic clues, and elicitation. Ellis (2012) defines consciousness-raising tasks as "pedagogic activity where the learners are provided with L2 data in some form and required to perform some operation on or with it, the purpose of which is to arrive at an explicit understanding" of the target grammar.

\section{Theoretical \&Empirical Studies on Focus on Form}

In this part, both theoretical and experimental research studies conducted on FoF and FoFs will be discussed. The basic tenet of FoF instruction is to comprehend meaning while learners' 
attention is directed to the linguistic units which are crucial for learners to comprehend the meaning. The need for FoF usually stems from learners' inabilities to use certain linguistic units accurately, which might lead to communication problems. These problematic linguistic units become the focus of language instruction so that learners could get back on track. As learners are unable to deal with these difficulties using their own resources, they cannot notice the linguistic traits of the target language during communicative activities. Therefore, a kind of intervention regarding these linguistic traits might be necessary to help learners cope with the challenges in their interlanguage systems (Ellis, 2009).

Over the past two decades, the impact of FoF instruction in the field of second language acquisition (SLA) has often been demonstrated through a number of theories and studies. According to Long (1991), while FoF instruction attaches importance to communicative and meaning-based language teaching practices, it also accepts the value of occasional shift from meaning to overt analysis of problematic linguistic units, which could be attributed to traditional non-communicative teaching practices. According to Norris and Ortega (2000), there have been several studies that have gathered evidence for the positive impact of FoF instruction on second language (L2) learners' acquisition of L2 morpho-syntactic forms.

Larsen-Freeman (2001) also indicates that even though it is possible for some learners to grasp the linguistic form of the language as a result of being exposed to the target language, there are few learners who can achieve this and it is particularly difficult for learners who are post pubescent or whose chance of being exposed to the target language is limited to the classroom as in many EFL contexts. Lightbown and Spada (2008) also indicate that when FoF instruction is not applied, certain structures may not be used by learners at all. In addition, some of the errors that students make could be fossilized in their interlanguages. Regarding this issue, Ellis (2012) asserts that problematic overgeneralizations done by learners might require negative evidence either through an explicit grammatical explanation or through corrective feedback so that learners are informed about their inaccurate linguistic productions. In addition, Ellis (2015) states that a number of studies related to the possible effects of FoF instruction and providing feedback on students' errors demonstrated that FFI instruction lead to significant gains related to the target forms.

There have been also many empirical studies conducted to investigate the effectiveness of FFI during the last three decades. In their study, Othman and Ismail (2008) attempted to investigate the effects of applying planned FoF instruction on the participants' accuracy regarding the use of the past simple tense and the past perfect tense. The results of the study indicated that the treatment group who received planned FoF instruction demonstrated a higher accuracy in their production of past simple tense and past perfect in comparison with the control group. The treatment group also produced much greater frequency of accurate forms than the control group.

Saeidi et al. (2012) carried out a study to investigate the effectiveness of FoF, Focus on Meaning (FoM) and FoFs in teaching vocabulary in ESP context. At the end of the study, it was found that the participants in FoF group attained significantly higher grades than the other participants in FoM and FoFs. On the other hand, the participants in FoM group achieved significantly higher scores than FoFs group. In another study, Abdolmanafi (2012) attempted to investigate the effects of three different types of treatment, namely FoFs, FoM and FoF, on the acquisition of English relativization. The study found that although all of the participants in three groups increased their grades from pretest to posttest, the participants in the FoF group were observed to have made the greatest progress. They were followed by the participants in FoFs group, and then the participants in the FoM group, in terms of sentence combining test and grammaticality judgment test. Shintani (2013) also investigated the comparative effectiveness of input-based FoF and production-based FoFs on vocabulary acquisition. At the end of the study, it was found that even though both types of instruction were effective for the acquisition of nouns, the FoF instruction was found to be more effective for the acquisition of adjectives. In addition, only the FoF learners developed the knowledge needed to use the adjectives in free production. 
Teaching Grammar through Form-Focused Instruction: The Case of Teaching Modal Verbs to Turkish EFL Learners

In another study, Kimura (2014) aimed to explore possible effects of FoF and FoFs instruction on the acquisition of the target English relative clause items by a group of adult learners in Japan. The results of the study indicated that both FoF and FoFs groups showed a significant improvement in the immediate post-test. However, the participants were given a delayed post-test after one month to investigate the acquisition of the selected forms. It was found that the accuracy rate of the productions by FoF group were slightly higher than the FoFs group. Nourdad and Aghayi (2014) conducted a study with a view to exploring the effect of FoF instruction on learning the passive voice of 12 English verb tenses. The results of the study have revealed a statistically significant difference between the two groups of FoFs and FoF instruction with FoF group outperforming the FoFs group.

Ebrahimi, Rezvani and Kheirzadeh (2015) carried out a study to investigate the impact of FoF and FoFs instruction methods on the acquisition of conditional sentences. The participants of the study were Iranian EFL learners who had intermediate level of language proficiency. The findings of this study revealed that learners in both groups did not differ significantly from each other in terms of their acquisition of conditional sentences. Therefore, it can be concluded that FoF instruction does not have any significant effect on the participants' acquisition of conditional sentences. Interestingly, it was also revealed that the participants in FoFs group attained a higher mean score on the post-test compared to focus-on-form group. In another study, Ranjbar, Amalsaleh and Shirazi (2015) attempted to investigate how the FFI affects lower intermediate EFL Iranian learners' grammar learning. According to the results, the experimental group, who received FFI, had significantly outperformed the control group, who received the traditional method of teaching grammar. As a result, FFI positively affected lower intermediate EFL Iranian learners' grammar learning.

In another study, Al-Qeyam and Bataineh (2016) conducted a study to examine the potential effect of form-focused pragmatic instruction on Jordanian EFL university students' acquisition and retention of pragmatic knowledge. At the end of the study, they found that there was a statistically significant difference in the students' grades on both in the immediate and delayed post-tests with FFI group outperforming the control group who received the prescribed teaching method in the text book. These findings suggest that pragmatic FFI positively affects the students' acquisition of pragmatic knowledge in comparison with the teaching method prescribed in the text book of the participants.

Bandar and Gorjian (2017) conducted a study to explore the visible impacts of FFI and FoM on the learning $W h$-questions on intermediate EFL learners at high school in Khorramshahr, Iran. The results of the study revealed that FoM has positively affected the learning of Wh-questions by Iranian EFL learners at the senior high school. There was a positive relationship between FoF and learning of Wh- questions by Iranian senior high school EFL learners. Overall, both FoF and FoM were effective in teaching Wh-questions. However, the results of this research revealed that learners in FoFs group achieved significantly higher scores than those in the FoF. These findings showed that using FoFs tasks were effective in language learning. In another study, Teng (2018) attempted to explore acquisition of phrasal verbs through two different instructional approaches: FoF and FoFs. The test results indicated that the FoFs group outperformed the FoF group for the three tests.

In another study, Arslan and Doğan (2020) attempted to investigate the effectiveness of planned FoF method in the acquisition of certain language forms and functions in a selected textbook unit. More specifically, their study examined the planned FoF method and the teaching model in the textbook of the 5th graders in terms of the attainment of the objectives of the target unit "Health". The findings of the study revealed that both treatment types helped learners increase their scores from pretest to progress achievement test and from pre-test to post-test. However, planned FoF was proved to be dramatically superior to the teaching model in the textbook based on the progress achievement tests conducted during the study.

\section{METHODOLOGY}

The present study adopted a mixed-method research design. The quantitative part involved a pretest, a treatment stage, and a posttest while the qualitative part consisted of written semi-structured 
interviews. The aim of this study was to explore the effectiveness of planned FoF instruction and FoFs instruction on a group of Turkish EFL students' learning of modal verbs. In order to find out the effect of each treatment (i.e. FoF and FoFs) on the participants' scores and explore their views on these treatments, the following research questions were examined:

1. Is there a difference between the effectiveness of FoF and FoFs methods in learning the target forms?

1a. Is there a statistically significant difference in the participants' test scores as a result of receiving planned FoF and FoFs instruction in the textbook?

2. What are the participants' views and opinions on the implementation and effectiveness of planned FoF and FoFs instruction?

\section{Participants}

The participants of the study consisted of $378^{\text {th }}$ grade students at a middle school in Denizli. These students were placed in two different intact classes. There were 18 students in the experimental group who received planned FoF instruction while the control group who received FoFs instruction included 19 students. The participants were selected due to their availability to the researcher. Therefore, it was convenience sampling being "easy, affordable and the subjects ... readily available" (Etikan, Musa, \& Alkassim, 2016, p. 2). Both instruction types were delivered online by the same teacher.

\section{Ethics committee approval}

The author confirms that ethical approval was obtained from Social and Human Sciences Research and Publication Ethics Committee, affiliated with Pamukkale University, Denizli. (Approval Date and No: 10.03.2021/ 05-11)

\section{Data collection}

This study aimed to investigate the effectiveness of planned FoF instruction and FoFs instruction on the learning of targeted modal verbs. In order to conduct the study, a number of instruments were used. First, a researcher-made multiple choice pretest was administered at the beginning of the study to determine the participants' existing level of knowledge with regard to the targeted modal verbs before the treatment. The content of the pretest was determined with another colleague who holds a PhD degree in the field. Each question and its options were carefully checked in terms of intelligibility and clarity with the help of the same colleague, and by doing so the intelligibility and clarity of the questions and options were ensured. After the treatments, a multiple choice posttest, which was prepared by the same researcher, was applied to both groups to measure the effectiveness of each instruction type. The posttest was an equivalent of the pretest in terms of content (i.e. modal verbs). In fact, the same pretest was applied as the posttest with minor modifications (i.e. different subjects, use of synonyms) in case the participants memorized their responses on pretest and got familiar with the test items, which would increase the risk of "threat to internal validity" in terms of testing (Cresswell, 2009, p.164). The same procedures regarding the content and intelligibility were carried out for the posttest as well. The piloting of pretest and posttest was conducted with another group of $8^{\text {th }}$ grade students studying at the same school. The scores of these tests were subjected to Kuder-Richardson 20 (KR20) analysis through SPSS.17 with a view to calculating the reliability coefficients or the consistency of the items in the tests (Şen, 2017). This analysis revealed that the internal consistency of the test items of the pre-test and post-test was at an acceptable level (Cronbach's Alpha .719 and .706 respectively). As the last step, written semi-structured interviews were conducted with 8 of the experimental group participants to explore their views on planned FoF instruction. As for the materials used in the study, planned FoF instruction involved researcher-made materials on modals while FoFs instruction was delivered through the textbook of the participants as well as some other teaching materials at hand. 


\section{Treatment procedure}

This study was conducted at a middle school in Denizli. First, a pretest was applied to make sure that the participants in the two groups did not differ significantly at the beginning of the study in terms of their knowledge of modal verbs. Both planned FoF and FoFs instructional sessions were delivered online. Each group received three hours of instruction in a week, and the treatment lasted three weeks. The duration of the treatment was determined according to the English syllabus of the school. On each day, different types of modal verbs with specific functions were taught by the same instructor. After the pretest, the participants in the experimental group received planned FoF instruction while the participants in the control group received FoFs instruction. The target forms in the present study were selected based on the syllabus followed at the school of the participants.

In planned FoF group, grammar instruction and communicative language use were combined. First, the participants were exposed to the target forms through a PowerPoint Presentation which involved all the target forms in meaningful sentences that were accompanied with visuals. Then the teacher focused learner's attention on modal verbs while accomplishing communicative activities and materials such as reading passages, dialogues, task cards and visual cues, which were also prepared by the researcher. During this process, the teacher utilized several FoF techniques such as input flood, input enhancement, input processing, corrective feedback (recasts), consciousness raising tasks, and interaction enhancement through pair-work activities within the scope of planned FoF (Doughty \& William, 1998). The teacher used an indirect, context-based presentation of grammar forms, rather than overt, teacher-led instruction in order to enable the learners to recognize the properties and functions of modal verbs in context. In this way, the learners had a chance to guess the meanings in context and come up with rules by themselves. During each session, different modal verbs with different functions were taught to the participants.

In short, the learners first were exposed to compressible input through a PowerPoint presentation so that they could get familiar with the target forms. Then, were given several written and visual materials (input flood) in which target forms were highlighted (input enhancement) so that they could comprehend the structures and functions of these target forms (input processing). After reading the passages or dialogues, the participants were asked to practice the modal verbs in different contexts (interaction enhancement) while concentrating on meaning. They were provided corrective feedback by the teacher when necessary (recasts). The activities that were designed for the treatment in the experimental group and their learning outcomes are presented in Table 1.

Table 1. The activities and expected outcomes for the experimental group

\begin{tabular}{cl}
\hline Activity & Expected Outcome \\
\hline Input Flood & $\begin{array}{l}\text { Notice the target forms by being } \\
\text { exposed to visual input. }\end{array}$ \\
Input processing & $\begin{array}{l}\text { Notice the target forms that are } \\
\text { written in bold or italics. }\end{array}$ \\
Consciousness Raising Tasks & $\begin{array}{l}\text { Read the dialogues and matches the } \\
\text { functions with the target forms. } \\
\text { Looks at the visuals and write an } \\
\text { appropriate sentence. }\end{array}$ \\
& $\begin{array}{l}\text { Notice the features of the target forms } \\
\text { by answering the teacher's questions. }\end{array}$
\end{tabular}


In FoFs instruction group, the participants were exposed to the target forms through a PowerPoint Presentation which involved all the target forms in meaningful sentences that were accompanied with visuals. The aim of this activity was to make learners notice the target forms in a meaningful way. However, the instructor deductively and explicitly provided the rules for the learning of modal verbs and their functions with this group using the grammar sections of the textbook. The instructor even made use of L1 when necessary. Students were then asked to carry out the activities based on the grammar focus boxes in their textbooks. As the next step, they were given additional materials such as worksheets and short quizzes so that they could reinforce their learning. Lastly, meaning-based activities through reading texts and dialogues were carried out with the participants. In short, the grammatical forms, modal verbs in this case, were basically taught in the form of Presentation-Practice-Production (PPP). The activities that were applied during the treatment in the control group and their learning outcomes are presented in Table 2.

Table 2. The activities and expected outcomes for the control group

\section{Activity Expected Outcome}

Gap filling

Dialogue completion

Rewriting

Reading

Quiz
Complete the sentences with appropriate modal verbs

Read the dialogues and complete the missing parts with appropriate modal verbs

Rewrite the given sentences using modal verbs

Read a text and answer true/false questions

Evaluate his/her learning

\section{Data analysis}

For the present study, a pretest - posttest design was employed in order to measure the effects of planned FoF instruction and FoFs instruction. The data obtained from the pretest and posttest were statistically analyzed through SPSS 17.0 with the aim of measuring the effectiveness of the two instructional treatments. First, a pretest was run to assess participants' existing knowledge of modal verbs in focus. As the total number of participants was less than 50, the p values of Shapiro-Wilk tests were checked. Since the $\mathrm{p}$ values were bigger than 0.05 , it was found the data followed a normal distribution. As the distribution of the data was normal, an independent samples t-test was conducted between the pretest scores of the two groups in order to see whether there was a statistically significant difference between the two groups prior to the study. In addition, a paired-samples t-test was applied. The aim of the paired-samples t-test was to compare the obtained mean scores of the participants in planned focus-on-form group on the pretest and posttest to demonstrate the effectiveness of the treatment. Next, another paired-samples t-test was carried out to explore the effectiveness of FoFs instruction. Then the between group comparisons of the posttest scores were carried out through 
independent samples t-test in order to analyze whether there was a statistically significant difference between the scores of the participants in both groups. The independent samples t-test of the posttest scores aimed to reveal which instructional treatment was more effective in learning the target forms at the end of the treatment process. Lastly, written semi-structured interviews were conducted to explore the views of the participants on the implementation and effectiveness of planned focus-on-form instruction. The student interviews were translated into English by the researcher and cross-checked by another colleague. Next, the transcribed data was analyzed through pattern- coding process (Miles \& Huberman. 1994) to identify recurrent themes. Having coded the whole transcribed data, similar codes were grouped while overlapping and/or redundant codes were reduced. Lastly, the frequencies and percentages were calculated through the number of responses with the same codes in each category. In order to ensure the reliability of the analysis of the qualitative data, a colleague also analyzed a quarter of the data as supported by Creswell (2007).

\section{FINDINGS}

Following the data analysis, findings of the present study regarding the research questions will be presented below.

R.Q.1: Is there a difference between the effectiveness of FoF and FoFs methods in learning the target forms?

In order to answer the research questions stated above, a number of t-tests were applied. Firstly, the analysis of the pretest scores revealed that there was not a statistically significant difference between the two groups $(\mathrm{t}(0.25), \mathrm{p}=0.80)$ prior to the treatment (see Table 3 ). The total

\begin{tabular}{llllllll}
\hline & $\mathbf{N}$ & Mean & $\mathbf{S}$ & $\mathbf{d f}$ & $\mathbf{t}$ & $\mathbf{p}$ \\
\hline \multirow{3}{*}{ Pretest } & Control Group & 19 & 36.3 & 17.5 & 35 & -.25 & .80 \\
Scores & Experimental Group & 18 & 37.5 & 9.7 & & & \\
\hline
\end{tabular}

score of the pretest was determined as 100. As for the mean statistics of both groups, the results also indicate that the mean score of the FoFs (i.e. control) group is 36.3 and the mean score of the FoF (i.e. experimental) group is 37.5 . Hence, it could be concluded that the prior knowledge of both groups didn't differ notably in terms of the target forms.

Table 3. Results of the independent samples t-test for the pretest scores

Next, in order to investigate the effectiveness of each instruction method, a paired-samples ttest was run. The aim of the t-test was to compare the obtained mean scores of the participants in each group on the pretest and posttest to demonstrate the effectiveness of each treatment. Table 4 and Table 5 below show the descriptive statistics and the results of paired samples t-test for FoFs (i.e. control) group.

Table 4. Paired samples statistics for the control group

\begin{tabular}{lllll}
\hline & N & Mean & S & S.E \\
\hline Pair I & & & & \\
Pretest & 19 & 36.3 & 17.5 & 4.02 \\
Post-test & 19 & 45.2 & 13.7 & 3.16 \\
\hline
\end{tabular}

Table 5. Paired-samples t-test results for the control group paired differences

$\begin{array}{llllll}\text { Mean } & \text { S } & \text { S.E } & t & \text { df } & \operatorname{sig}(2 \text {-tailed })\end{array}$




\begin{tabular}{lllllll}
\hline Pair I Pretest-Posttest & -8.9 & 8.7 & 2.0 & -.4 .4 & 18 & .000
\end{tabular}

Table 4 shows that the mean score obtained on the post-test (45.2) is much higher than the one obtained on the pre-test (36.3). In addition, Table 5 indicates that there is a significant difference between the scores obtained from the pretest and posttest ( $\mathrm{p}=.00)$. Therefore, it can be concluded that FoFs instruction has a significant effect on the participants' learning of target forms.

Another paired-samples t-test was run to investigate the effects of planned FoF instruction. Table 6 and Table 7 show the descriptive statistics and the results of paired samples t-test for FoF (i.e. experimental) group.

Table 6. Paired samples statistics for the experimental group

\begin{tabular}{lcccc}
\hline & N & Mean & S & S.E \\
\hline Pair I & & & & \\
Pretest & 18 & 37.5 & 9.7 & 2.2 \\
Posttest & 18 & 56.9 & 16.9 & 3.9 \\
\hline
\end{tabular}

Table 7. Paired-samples t-test results for the experimental group paired differences

\begin{tabular}{lcccccc}
\hline & Mean & S & S.E & t & df & $\operatorname{sig}(2$-tailed) \\
\hline Pair I Pretest-Posttest & -19 & 19.1 & 4.5 & -.4 .3 & 17 & .000 \\
\hline
\end{tabular}

Table 6 shows that the mean score obtained on the post-test (56.9) is much higher than the one obtained on the pre-test (37.5). In addition, Table 7 indicates that there is a significant difference between the scores obtained from the pretest and posttest $(\mathrm{p}=.00)$. Therefore, it can be concluded that planned FoF instruction has also a significant effect on the participants' learning of target forms.

Considering these findings, it could be concluded that although both groups demonstrated improvement after the treatments, the participants who received planned FoF instruction were observed to attain higher test scores compared with FoFs group participants. Therefore, FoF instruction was proved to be more effective than FoFs instruction for the participants.

R.Q.1a: Is there a statistically significant difference between the participants' test scores as a result of receiving planned FoF and FoFs instruction?

In order to answer the research question stated above, between group comparisons of the posttest scores were conducted through independent samples t-test to see whether there was a statistically significant difference between the posttest scores of the participants in both groups. Table 8 and Table 9 shows the descriptive statistics and the results of paired samples t-test for both groups.

Table 8. Independent samples t-test statistics for both groups

\begin{tabular}{llllll}
\hline & & N & Mean & S & SE \\
\hline \multirow{2}{*}{ Post-test } & Control Group & 19 & 45.2 & 13.7 & 3.1 \\
Scores & Experimental Group & 18 & 56.9 & 16.9 & 3.9 \\
\hline
\end{tabular}


Table 9. Independent samples t-test statistics for posttest scores

\begin{tabular}{lcccccc}
\hline \multicolumn{7}{c}{ Levene's Test for Equality of Variances } \\
& F & Sig & t & df & $\operatorname{sig}(2$-tailed) & Mean D. \\
\hline Score & .995 & .325 & -2.3 & 35 & .027 & -11.6 \\
Equal variances & & & & & & \\
Assumed & & & & & & \\
\hline
\end{tabular}

Table 8 shows that the mean score of the experimental group $(M=56.9)$ is higher than that of control group (M=45.2). In addition, Table 9 indicates that there is a significant difference between the posttest scores of the two groups ( $\mathrm{p}=.027$ ). Therefore, it can be concluded that planned FoF instruction is superior to FoFs instruction in terms of its effect on the participants' learning of target forms.

\section{Findings from Interview}

R.Q. 2. What are the participants' views and opinions on the implementation and effectiveness of planned FoF and FoFs instruction?

In order to answer the research question stated above, written semi-structured interviews were conducted with 8 of the participants in FoF group. As FoF was a new teaching method for them, it was worth exploring their views on the issue. The responses to the interview questions were content analyzed. The analysis of each question was separated under a category. For the data collected through the written interviews, content analysis was implemented and the 8 participants' responses were categorized under recurring responses. For this purpose, the interview questions listed below were given on the basis of the last research question of this study:

1- $\quad$ Do you prefer learning grammar through FoF instruction or do you prefer receiving explicit grammar instruction through FoFs method?

2- How did FoF instruction affect your learning of grammar?

The interviews were conducted in Turkish, and thus they were translated into English by the researcher. A content analysis was conducted by the researcher together with another rater to reach more reliable results. The themes gathered as a result of the content analysis are shown below in Table 10.

Table 10. Themes about form-focused instruction by the participants

\begin{tabular}{ll}
\hline Participants & Themes \\
\hline P1, P2, P3, P4, P6, P8 & Guessing the Meaning \\
P1, P2, P3, P6 & Permanent Learning \\
P2, P4, P5 & Exam Success
\end{tabular}

Table 10 clearly indicates that most of the participating students favored focus-on-form instruction since it enabled them to guess the meaning of words or other grammatical structures. Regarding this issue, the most striking statements of the participants will be presented. For instance, 
P1 said "When too many rules are given explicitly at the same time, I feel confused and bored. During the meaning-focused activities, I was able to guess the meanings by myself. I learned better this way." Also, P4 said "It was like doing a puzzle for me. I learned and enjoyed the at the same time."

Another theme that emerged was permanent learning. Related to this issue, P1 said "I think that learning grammar through a reading text is better because I remember not only the rules but also how those rules are applied in a sentence." P6 said "I remember the rules of the modal verbs better and I can even use them communicatively."

Lastly, some of the participants mentioned the effectiveness of the focus-on-form instruction on their exam success. On this issue, $\mathrm{P} 4$ said "I learned the grammar rules better through reading texts and dialogues, so I didn't have much difficulty in answering the tests questions." Considering the themes emerged, it can be concluded that the participants were satisfied with the FoF instruction mainly because the participants preferred guessing the meanings out of the context rather than receiving too many isolated grammatical rules. They also believe that they retain the knowledge for a longer period of time in this way. Lastly, they think that their exam scores are positively affected by FoF instruction.

\section{DISCUSSION, CONCLUSION AND SUGGESTIONS}

The findings of the present study revealed that the participants who received FoF instruction made much more progress than the participants in FoFs group. The findings of this study are in line with several studies conducted before (Othman \&Ismail, 2008; Nourdad \&Aghayi,2014; Al-Qeyam \& Bataineh,2016; Arslan \& Doğan,2020). Othman and Ismail (2008) conducted a study regarding the use of the past simple tense and the past perfect tense and found that FoF group demonstrated a higher accuracy in their production of past simple tense. The reason for this could be the fact that learners in FoF group are exposed to a great amount of comprehensible input and gain mastery over the target forms both in their structural use and functional ones. Likewise, Nourdad and Aghayi (2014) found that FoF instruction was more effective in learning the passive voice of 12 English verb tenses. The reason for this finding could be that there are a lot of tenses and their passive versions, which could be challenging for learners to acquire when the rules are given as isolated items. In FoF, however, they are taught through meaningful activities. In another study, Al-Qeyam and Bataineh (2016) found that the potential effect of form-focused pragmatic instruction regarding the acquisition and retention of pragmatic knowledge was superior than the effect of prescribed teaching method in the text book. Lastly, Arslan and Doğan (2020) conducted a study and found that planned FoF was dramatically superior to the teaching model in the textbook based on the progress achievement tests applied during the study.

On the other hand, a number of studies yielded different results compared to the present study. (Ebrahimi, Rezvani \& Kheirzadeh, 2015; Bandar \& Gorjian,2017; Teng, 2018). To start with, Ebrahimi, Rezvani and Kheirzadeh (2015) conducted a study and found that both FoF and FoFs instruction methods had similar effect on the acquisition of conditional sentences. In fact, the participants in FoFs group attained a higher mean score on the post-test compared to FoF group. The reason for this could be that the participants were accustomed to explicit grammar instruction and their exams might have consisted of discrete test items. In another study, Bandar and Gorjian (2017) investigated the visible impacts of FFI and focus on meaning (FoM) on the learning Wh-questions on intermediate, and found that even though FoF and FoM were effective in teaching Wh-question, FoFs group achieved significantly higher scores than those in the FoF. These findings showed that using FoFs tasks were effective in language learning. It can also be stated that FoFs could be an effective method for teaching specific linguistic items in certain contexts. Lastly, Teng (2018) attempted to explore acquisition of phrasal verbs through two different instructional approaches (i.e. FoF and FoFs) and found that the FoFs group outperformed the FonF group for the three tests. The reason for this finding could be that learning phrasal verbs require explicit teaching and so that learners could memorize their meanings. 
As one can see, there have been many studies conducted on the effectiveness of FFI. While some studies found FoF more effective, others revealed that FoFs were superior to FoF. The contradictory findings of these studies indicate that there could be other factors affecting the results of these instruction types. The context, participants, length of the study, or the target forms might all have an impact on the effectiveness of each instructional treatment, which could lead to differences in language learning as well. In short, it can be concluded that although wide range of research has been conducted on the effects of different kinds and techniques of FFI, research findings have not been conclusive regarding the superiority of either one. As for the views of the participants, it could be stated that the participants were satisfied with the FoF instruction since they preferred guessing the meanings out of the context rather than receiving too many isolated grammatical rules. They also favored FoF instruction since it helped them retain the knowledge for a longer period of time. Lastly, they think that their exam scores are positively affected by FoF instruction.

The findings of this study could have some pedagogical implications for many stake holders in the field of language education. To start with, textbook writers or curriculum developers could integrate more FoF activities and exercises into their materials. Even if appropriate FoF materials are available, teachers need to be trained on how to integrate FoF approach with these materials effectively. As language learners in Turkey have been receiving grammar-focused instruction for years, their language skills such as listening, speaking, and writing haven't reached the desired levels. Therefore, it is teachers' responsibility to be aware of different FFIs so that they could help their students improve these skills through FoF techniques with various meaning-focused communicative activities. Also, considering the benefits of FoF instruction reported in this study, language teachers could be advised to provide a great amount of comprehensible input for their students through different visual and audio materials. They should also focus their students' attention on the meaning while occasionally pointing out the grammatical structures in those materials. By doing so, they will ensure that their students' priority will be on comprehending the meaning rather than memorizing grammatical structures.

Lastly, it should be noted that there are several limitations of the present study. Therefore, the findings of the present study need to be interpreted considering these limitations. First, the sample size could be a limitation as there were 37 participants in the study. Therefore, the findings cannot be generalized to all English language learners. In addition, the present study only focused on teaching modal verbs through certain techniques of FFI. Another study might yield different results with other structures in English. Last but not least, the effectiveness and reliability of online education could be a limitation since the participating teacher couldn't manage the treatment process in person. In short, future research needs to consider these limitations and design a study accordingly.

\section{REFERENCES}

Abdolmanafi, S. (2012). Effects of form-focused instruction on the learning of relative clauses. Journal of Language and Linguistic Studies,8(1),0-210.Retrieved from https://dergipark.org.tr/tr/pub/jlls/issue/9935/122952.

Aktaş, T. (2005). Yabanci dil öğretiminde iletişimsel yeti. Journal of Language and Linguistic Studies, $1(1), 89$.

Al-Qeyam, F. R., Bataineh, R. F., \& Smadi, O. M. (2016). The effect of form-focused instruction on learning and retaining pragmatic knowledge among Jordanian EFL tertiary-level learners. Journal of International Doctoral Research, 5(1), 28-50.

Arslan, R. \& Işık-Doğan, S. (2020). Investigating the effectiveness of planned focus on form method in teaching young learners English as a foreign Language. Journal of Language and Linguistic Studies, 16 (1), 418-439.doi: 10.17263/jlls.712869.

Bandar, B., \& Gorjan, B. (2017). Teaching Grammar to EFL learners through focusing on form and meaning. Journal of Applied Linguistics and Language Learning 2017, 3(4): 88-96.

Creswell, J. W. (2009). Research design: Qualitative, quantitative, and mixed methods approaches (3rd ed.). Sage Publications, Inc. 
Dekeyser, R.M. (1998). Beyond focus on form: cognitive perspectives on learning and practical second language grammar. In C. Doughty \& J. Williams (Eds.), Focus on form in classroom second language acquisition (pp. 42-63). Cambridge, UK: Cambridge university Press.

De la Fuente, M. J. (2002). Negotiation and oral acquisition of Spanish L2 vocabulary: the roles of input and output in the receptive and productive acquisition of words. Studies in Second Language Acquisition 24: 81-112.

Doughty, C., \& Williams, J. (1998). Issues and terminology. In C. Doughty and J. Williams (Eds.), Focus on form in classroom second language acquisition (pp. 1-11). Cambridge: Cambridge University Press.

Ebrahimi, S., \& Rezvani, \& E., Kheirzadeh, S. (2015). Teaching grammar through FormS focused and form focused instruction: The case of teaching conditional sentences to Iranian intermediate EFL learners. Journal of Applied Linguistics and Language Research 2 (1), 10-25.

Ellis, R. \& He, X. (1999). The roles of modified input and output in the incidental acquisition of word meanings. Studies in Second Language Acquisition 21: 285-301

Ellis, R. (2001). Introduction: Investigation of form-focused instruction. Language Learning, 51, Supplement 1, 1-46.

Ellis, R. Basturkmen, H., \& Loewen, S. (2002). Focusing on form in the classroom. Diverse Voices, 2, 168-188.

Ellis, R. (2005). Instructed second language acquisition. Department of Applied Language Studies and Linguistics. The University of Auckland.

Ellis, R. (2008). Investigating grammatical difficulty in second language learning: Implications for second language acquisition research and language testing. International Journal of Applied Linguistics, 18, 4-22. DOI: https://doi.org/10.1111/j.1473- 4192.2008.00184.x.

Ellis, R. (2009). Task-based language teaching: Sorting out the misunderstandings. International Journal of Applied Linguistics, 19(3), 229-246. https://doi.org/10.1111/j.14734192.2009.00231.x

Ellis, R. (2012). The study of second language acquisition (2nd ed.). Oxford, UK: Oxford University Press.

Ellis, N. C. (2015). Implicit and explicit learning: Their dynamic interface and complexity. In P. Rebuschat (Ed.), Implicit and explicit learning of languages (pp. 3-23). Amsterdam: John Benjamins.Implicit_AND_Explicit_Learning_EllisPreprint.pdf

Etikan, I., Musa, S. A., \& Alkassim, R. S. (2016). Comparison of convenience sampling and purposive sampling. American Journal of Theoretical and Applied Statistics, 5(1), 1-4. doi: 10.11648/j.ajtas.20160501.11.

Farrokhi, F., \& Chehrazad, M.S. (2012). The effects of planned focus on Form on Iranian EFL learners 'oral accuracy. World Journal of education, 2(1), 70-81.

Harmer, J. (1989). The practice of language teaching (3rd ed.). Completely revised and updated, New York.

Işık, A. (2008). Yabancı dil eğitimimizdeki yanlışlar nereden kaynaklanıyor? Journal of Language and Linguistics, 4(2), 15-26.

Kimura, N. (2014). Differential effects of focus on form and focus on forms on English relative clause by EFL learners in Japan, Journal of Educational Research,29; 29-39.

Krashen, S. D. (1981). Second language acquisition and second language learning (1st ed.) [Internet edition]. Retrieved from http://www.sdkrashen.com/content/books/sl_acquisition_and_learning.pdf

Larsen-Freeman, D. (2001). Teaching grammar. In M. Celce-Murcia (Ed.), Teaching English as a second or foreign language (3rd ed., pp. 251-266). USA: Heinle \& Heinle Thomson Learning.

Lightbown, P. M., \& Spada, N. (2008). Form-focused instruction: Isolated or integrated? Tesol Quarterly. 42(2), 181-207. Retrieved March 25, 2021, from http://www.jstor.org/stable/40264447DOI: 10.1002/j.1545-7249. 2008.tb00115. x.

Long, M.H. (1991). Focus on form: a design feature in language teaching methodology. In K.de Bot, R. Ginsberg, \& C. Kramsch (Eds.), Foreign language research in cross cultural perspective (pp.39-52). Amsterdam: John Benjamins. 
Teaching Grammar through Form-Focused Instruction: The Case of Teaching Modal Verbs to Turkish EFL Learners

Long, M.H. (1996). The role of the linguistic environment in second language acquisition. In W.C. Ritchie, \& T.K. Bhatia (Eds.), Handbook of second language acquisition (pp.413-468). San Diego, CA: Academic Press.

Long, M. H., \& Robinson, P. (1998). Focus on form: Theory, research, and practice. In C. Doughty \& J. Williams (Eds.), Focus on form in classroom second language acquisition (pp.15-63). Cambridge: Cambridge University Press.

Long, M. H. (2000). Focus on form in task-based language teaching. In R. Lambert \& E. Shohamy (Eds.), Language policy and pedagogy. Essays in honor of A. Ronald Walton (pp. 179-192). Philadelphia: John Benjamins.

Miles, M, B., \& Huberman, A. M. (1994). Qualitative data analysis: An expanded sourcebook. (2nd ed). Thousand Oaks, CA: Sage.

Norris, J. M., \& Ortega, H. (2000). Effectiveness of L2 instruction: A research synthesis and quantitative meta-analysis. Language Learning, 50(3), 417-528.

Nourdad, N., \& Aghayi, E. T. (2014). Focus on form in teaching passive voice of different tenses. Procedia-Social and Behavioral Sciences, 98, 1400-1408.

Oğuz, E. (1999). Illköğretimde yabancı dil (İngilizce) öğretimi sorunlart (The Problems of foreign language (English) teaching in elementary schools). Unpublished Master Thesis. Kocaeli University: Kocaeli.

Othman, J., \& Ismail, L. (2008). Using focus on form instruction in the teaching and learning of grammar in a Malaysian classroom. The Journal of Asia TEFL,5(2), 93-115.

Paker, T. (2007). Problems of teaching English in schools in Çal Region and suggested solutions. 21. Yüzyıla Girerken Geçmişten Günümüze Çal Yöresi: Baklan, Çal, Bekilli. Çal Yöresi Yardımlaşma ve Dayanışma Derneği Yayını, 3, 684-690

Ranjbar, S., Amalsaleh, E., \& Shirazi, Z. H. R. (2015). The effects of form-focused instruction on lower intermediate EFL Iranian learners' grammar learning. International Online Journal of Education and Teaching (IOJET), 2(2). 96-116.

Roothooft, H. (2014). The relationship between adult EFL teachers' oral feedback practices and their beliefs. System, 65, 65-79.

Saeidi, M., Zaferanieh, E., \& Shatery, H. (2012). On the effects of focus on form, focus on meaning, and focus on forms on learners" vocabulary learning in ESP context. English Language Teaching, 5(10), 72-79.

Schmidt, R. (1990). The role of consciousness in second language learning. Applied Linguistics, 11,129-158.

Schmidt, R. (2001). Attention. In P. Robinson (Ed.), Cognition and second language instruction (pp.332), Cambridge: Cambridge University Press.

Sheen, R. (2002). "Focus on form" and "focus on forms". ELTJ, 56(3), 303-305.

Shintani, N. (2013). The effect of focus on form and focus on forms instruction on the acquisition of productive knowledge of L2 vocabulary by young beginning-level learners. TESOL Quarterly, 47, 36-62.

Şen, S. (2017). Ölçme araçlarında bulunması gereken nitelikler. Retrieved from https://sedatsen.com/category/olcme-ve-degerlendirme/.

Teng, M. F. (2018). The effect of focus on form and focus on forms instruction on the acquisition of phrasal verbs by Chinese students. Asian EFL Journal, 20(6), 145-173.

Tilfarlioglu, F. Y. \& Öztürk, A. R. (2007). An analysis of ELT teachers' perceptions of some problems concerning the implementation of English language teaching curricula in elementary schools. Journal of Language and Linguistic Studies, 3(1), 202- 217.

Uysal, H. H., \& Bardakci, M. (2014). Teacher beliefs and practices of grammar teaching: Focusing on meaning, form, or forms? South African Journal of Education, 34(1),1- 16. 